\title{
EXPOSING THE FALSE PARADIGM USED \\ IN MANAGEMENT DECISION MAKING
}

\author{
Malan Smith \\ Siemens Telecommunications (Pty) Ltd \\ P.O. Box 912469 \\ Silverton 0127, South Africa
}

\author{
Pieter Pretorius \\ Department of Engineering and Technology Management \\ Faculty of Engineering, Built Environment and Information Technology \\ University of Pretoria \\ Pretoria 0002, South Africa
}

\begin{abstract}
This article discusses Economic Value Added (EVA) which is a popular shareholder value measurement. The main driving factors that influence EVA can be deduced from a modification of the Du Pont financial model. However, if these drivers are communicated to the organisation, and goals are set around achieving specific components of the drivers, the results achieved might be suboptimal. This is a direct consequence of the fact that the organisation is a system, and that EVA is an emergent property of the system. Systems theory should therefore be applied to discover the reasons for these counterintuitive outcomes in an organisation. Dilemmas (conflicts) in the system are a result of the paradigm used in understanding the system. A method to examine the conflicts that occur in a system is the three-cloud technique. By applying this technique, it is possible to find the root cause of suboptimal performance in organisations: the false underlying paradigm used in the decision making process. The incorrect paradigm is to assume that a local optimal outcome is equivalent to a global optimal outcome.
\end{abstract}

\section{OPSOMMING}

Hierdie artikel bespreek Ekonomiese Toegevoegde Waarde (ETW), 'n gewilde maatstaf van aandeel-houerwaarde. Die belangrikste drywers wat ETW beinvloed, kan afgelei word uit 'n gewysigde Du Pont model. Indien doelwitte in die organisasie rondom hierdie drywers in isolasie gestel word, kan die resultate suboptimaal wees. Die suboptimale resultate is 'n direkte gevolg van die feit dat die organisasie ' $n$ stelsel is, en dat ETW 'n stelseleienskap is. Stelselteorie moet dus toegepas word om die onderliggende redes vir hierdie suboptimale resultate te vind. Dilemmas (konflikte) binne 'n stelsel is 'n direkte resultaat van die paradigma wat gebruik word om die stelsel te verstaan. 'n Metode om die konflikte in 'n stelsel te ondersoek is die drie-wolk metode. Deur hierdie metode toe te pas, is dit moontlik om die grondliggende oorsaak van suboptimale prestasie in 'n organisasie te vind: die foutiewe bestuursparadigma wat vir besluitneming gebruik word. Die foutiewe paradigma is om aan te neem dat 'n positiewe lokale impak van 'n besluit sal lei tot 'n positiewe globale impak. 


\section{Introduction}

Performance measurements that align the rewards of management with the expectations of the shareholders of the business are increasing [1]. These type of measurements fall under the generic name of shareholder value measures [2]. General Electric is probably the most successful corporation that has adopted a particular shareholder value measure called Economic Value Added (EVA). The objective of a manager with an EVA performance measurement is to increase the EVA of the business. To be able to manage with this measurement, it is therefore necessary to determine the factors that influence EVA.

\section{The calculation of Economic Value Added}

In order to be able to calculate the EVA of a business, the rate of return on capital and the cost of the capital employed to generate that return must be calculated. The rate of return $r$ on the capital of the business is calculated as follows from the net operating profit after tax (NOPAT) [3]:

$$
r=\frac{\text { NOPAT }}{\text { capital }}
$$

The cost of capital, $c$, is the weighted average cost of debt, owners' equity and preferential shares. The calculation of EVA is then done as follows [3]:

$$
\begin{aligned}
\text { EVA } & =(\text { rate of return }- \text { cost of capital }) \times \text { capital } \\
& =(r-c) \times \text { capital } \\
& =r \times \text { capital }-c \times \text { capital } \\
& =\text { NOPAT }-c \times \text { capital } \\
& =\text { operating profits }- \text { a capital charge }
\end{aligned}
$$

Therefore, the EVA of a business is the operating profits generated minus a charge for the use of capital. This is exactly the same as the definition of residual income, therefore EVA is a variant of the capital budgeting method [2].

The Du Pont model. The Du Pont model is a financial model of a company that allows business performance to be analysed in terms of the utilisation of assets, the margins obtained in the business, and the leverage applied to equity through the use of debt. The model can be derived from the following equation for the return on assets (ROA) of the business:

$$
\begin{aligned}
\text { ROA } & =\frac{\text { Net profit }}{\text { Total Assets }}=\frac{\text { Net profit }}{\text { Turnover }} \times \frac{\text { Turnover }}{\text { Total Assets }} \\
& =\text { Net profit margin } \times \text { Asset turns }
\end{aligned}
$$

Therefore the return on assets of the business is determined by two ratios: the net profit margin earned on sales, and the efficient use of assets in the business as determined by the number of times the total assets of the business are turned over. 
The return on equity (ROE) is a function of the return on assets, but the financial leverage obtained through using debt is taken into account:

$$
\begin{aligned}
\text { ROE } & =\frac{\text { Net profit }}{\text { Equity }} \\
& =\frac{\text { Net profit }}{\text { Total Assets }} \times \frac{\text { Total assets }}{\text { Equity }} \\
& =\text { Return on assets } \times \text { Leverage }
\end{aligned}
$$

By substituting equation (5) into equation (4), the Du Pont model for analysing business performance is obtained:

$$
\mathrm{ROE}=\text { Net profit margin } \times \text { Asset turns } \times \text { Leverage }
$$

The return on equity of a business can therefore be increased from equation (6) in three ways:

- increase the net profit margin;

- increase the total asset turnover;

- increase the financial leverage.

Application of the Du Pont model to EVA. The Du Pont model identifies the factors that increase the return on equity. The approach in using EVA as a measure of operational performance, is to measure return on total assets, and to attach a cost to the assets in terms of a weighted cost of debt and equity. Substituting equation (1) into equation (2):

$$
\begin{aligned}
\text { EVA } & =(r-c) \times \text { capital } \\
& =\left(\frac{\text { NOPAT }}{\text { capital }}-c\right) \times \text { capital }
\end{aligned}
$$

However, the capital invested in the business is the same as the total assets utilised in the business, and if the business does not have large non-operative profits or losses, NOPAT and the net profit of the company is very similar, which modifies the first term of equation (7) to:

$$
\begin{aligned}
\text { EVA } & \approx\left(\frac{\text { Net profit }}{\text { assets }}-c\right) \times \text { assets } \\
& =(\text { return on assets }-c) \times \text { assets }
\end{aligned}
$$

From equation (4) it is known that return on assets is influenced by the net profit margin and the total asset turnover of the business. The influence of leverage in equation (6), is achieved 
through the change in the cost of capital as the amount of debt utilised increases. Therefore, according to equation (8), EVA can be increased in three primary ways:

- increase the net profit margin;

- increase the total asset turnover;

- decrease the cost of capital.

The last condition, to decrease the cost of capital, is different from increasing the financial leverage, as would be the recommendation when applying the Du Pont model. The cost of capital is a function of the risks of the business, and therefore there will be an optimum (minimum) cost of capital that will maximise the EVA of the business. If the Du Pont approach is followed, increased leverage will add increased returns on equity as long as the company can borrow. If the minimum cost of capital approach is followed, then the expected return on equity, and the cost of borrowing both are a function of the risk of the company, which is in return dependent on the capital structure of the company.

\section{An introduction to systems thinking}

It has been shown that EVA is a good measurement that, when it is implemented with the correct reward system, will align the interest of managers with those of the shareholders of the business [4]. However, there are several areas of influence on EVA as explained in the previous paragraph. Management must find a way to ensure that all managers are aligned on how to influence these factors, and that the activities of the workers are contributing to the improvement of these factors. In order to achieve these goals, and to gain insight into how management makes decisions, it is necessary to understand systems and systems thinking.

$\mathrm{O}$ 'Connor et al [5] defines a system as "an entity that maintains its existence and functions as a whole through the interaction of its parts." Ackoff defines a system as "a set of two or more elements that satisfies the following three conditions:

- The behaviour of each element has an effect on the behaviour of the whole;

- The behaviour of the elements and their effects on the whole are interdependent;

- However subgroups of the elements are formed, each has an effect on the behaviour of the whole and none has an independent effect on it" [6].

A system derives its properties from the interaction of its parts, therefore it cannot be taken apart and understood from the analysis of its components [6]. The properties of the system are the properties of the whole, and are not properties of the parts. These properties are called emergent properties [5]. The emergent properties of a system are created by the cause and effect interrelationships between the elements of the system. A form of cause and effect relationship is feedback. Feedback (output of the system re-entered as input), can be either reinforcing, or balancing feedback. Reinforcing feedback can lead to runaway (exponential) growth, while balancing feedback creates stability and resistance to change in a system [5]. The cause and effect relationships in a system create unexpected outcomes due to the following attributes of cause and effect relationships:

- "Cause and effect may be separated in time and space;

- Cause and effect can replace one another, displaying circular relationships; 
- An event may have multiple effects. The order of importance may shift in time;

- A set of variables that initially played a key role in producing an effect may be replaced by a different set of variables at a different time. Removing the initial cause will not necessarily remove the effect" [7].

The environment of a system is " $a$ set of elements, and their relevant properties, which elements are not a part of the system but a change in any of which can produce a change in the state of the system" [6]. A closed system is a system that has no environment, an open system is one that has an environment with which it interacts [6].

The organisation as a system. Gharajedaghi [7] refers to five characteristics that define an organisation as a system: openness, purposefulness, multidimensionality, emergent properties and counter-intuitive outcomes.

The organisation is an open system since its behaviour can only be understood in the context of the environment in which it functions. Since the environment of the organisation has a large impact on the system, it is necessary to be able to influence the environment. In a system, leadership has the meaning of "influencing what one cannot control and appreciating what one cannot influence" [7]. The transactional environment of the system is defined as the part of the environment where influence can be applied.

The organisation is a purposeful system in that it "produce not only the same outcomes in different ways in the same environment but different outcomes in both the same and different environments. It can change its ends under constant conditions" [7]. These characteristics of the system imply free will (choice). Since the participants in the organisation as a system (human beings) have free will to make choices, the world is not run by those who are rightthe world is run by those who can convince others that they are right. Although one tends to think that all choice is rational, there are three dimensions to choice: rational, emotional and cultural. Rational choice takes place when a person acts out of self-interest, and is by nature a risk-averse form of choice. Emotional choice is the choice that is associated with excitement, and is not risk-averse since risk is an important attribute of excitement and challenge. Cultural choice is the default choice that takes place in the confines of the ethical norms of society. To make choices, implies the power to make decisions, as well as the freedom to choose [7].

The dimensions of the system refer to the different aspects and facets exhibited by a system. The organisation exhibits multidimensionality since it has complementary relations in opposing tendencies and creates feasible wholes with unfeasible parts. In an organisation, opposing tendencies do not exist in dualities such as order/chaos, but these opposing tendencies tend to exist in a continuum of tendencies. The fact that opposing tendencies not only coexist and interact but form complementary relationships, is called the principle of multidimensionality [7].

An organisation has emergent properties: properties that are properties of the whole, and not a property of any of the parts. Management of the organisation plays a major role in the manifestation of emergent properties: "if success is an emergent property, then it has to be about managing interactions rather than actions" [7]. A winning team does not necessarily consist of all the best players, the interaction between the players is a big contributor to the success of the team. The EVA of an organisation is an emergent property that is a measure of the financial success of the organisation.

Organisations are counterintuitive since the actions intended to produce a desired outcome, may create the opposite outcome [7]. The counterintuitiveness of a system is a consequence of the interrelationships between causes and effects. 
From the above attributes of an organisation, it is clear that an organisation is a complex system, since it consists of beings with free will that can influence its environment. The complexity in an organisation can be managed to produce desirable outcomes, if a profound understanding of the system exists [8].

Causal loop diagrams. Causal loop diagrams are a way of illustrating the interrelationships between the elements of a system [9].

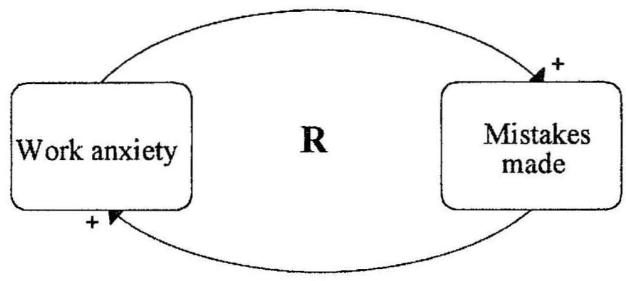

Figure 1. A balancing loop [9]

Figure 1 contains a balancing loop. The arrows indicate the direction of cause and effect. A "+" sign indicates that the effect changes in the same direction as the cause, i.e. an increase in the cause leads to an increase in the effect. A "." sign indicates that the effect changes in the opposite direction as the cause. The letter " $\mathrm{B}$ " indicates that it is a balancing loop. The word "delay" indicates that there is a time delay between the cause and the effect.

The causal loop diagram in Figure 1 can be read as follows: as the level of job stress increases, coping strategies against stress are increased. Over time, these coping strategies lower the level of job stress.

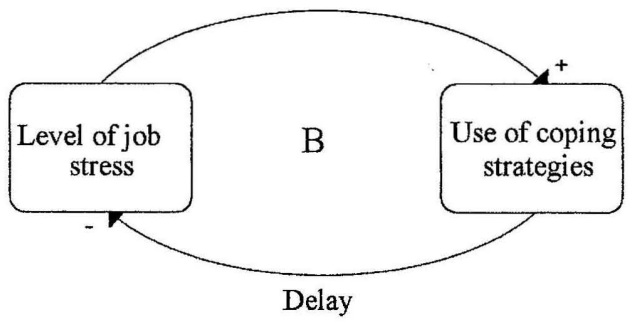

Figure 2. A reinforcing loop [9]

Figure 2 contains a reinforcing loop. The letter "R" indicates that the cause and effect relationship reinforce each other. The diagram can be read as follows: as the number of mistakes made increases, the level of anxiety at work increases. This increased anxiety causes the person to make more mistakes at work.

Causal loop diagrams can be applied to some simple strategies to increase EVA, and it offers an explanation of why these simple strategies fail. In the previous paragraph, reference is made to the three primary methods to increase EVA: increase the net profit margin, increase the total asset turnover and decrease the cost of capital. 




Figure 3. Reducing inventory to increase EVA

In Figure 3 the strategy to increase asset turnover through reducing the amount of assets is analysed. The balancing loop at the top of the diagram can be interpreted as follows: the need to increase EVA results in an increased reduction in inventories, which will increase EVA and therefore reduce the need to increase EVA. This is the intended effect. The reinforcing loop at the bottom shows the negative consequence: as inventories get reduced, over time the stock levels become too low and stock-outs occur. Sales orders are then lost due to the non-availability of stock. The result is that there is a greater pressure to increase EVA since lost sales results in lower EVA. Therefore the strategy to reduce stocks to increase EVA can lead to an unintended decrease in EVA.

In Figure 4 the strategy to increase EVA by eliminating products with a low profit margin from the portfolio is analysed. The balancing loop shows that the need to increase EVA results in pressure to reduce the number of low margin products. The intention is that the elimination of low margin products should allow the company to have a high margin per product, which should increase the net profit, margin. However, the unintended consequence is that total sales decreases, and overheads as a proportion of sales increases (since all overheads can usually not be cut), therefore the profit margins decrease and the pressure to increase EVA becomes bigger. A strategy to reduce the number of low margin products to increase the net profit margin of the company can therefore have the unintended consequence that the net profit margin actually decreases.

As can be seen, Figures 3 and 4 are exactly the same diagram, but with different words in the boxes. These repeated patterns that can be found in systems are called systems archetypes [9]. These examples illustrate the system archetype "fixes that fail." This archetype occurs when crisis are dealt with in isolation, or when the negative effects of fixes are not anticipated and eliminated [10]. 




Figure 4. Eliminating low margin products to increase EVA

\section{Decision making within a system}

Managers and workers have to make decisions constantly. In order to facilitate the decision process and let the system produce its output, it is necessary to form policies. Policies are standard practices which determine how the organisation functions as a system. Policies are written and unwritten. The organisation's culture determines how it sets priorities among different choices [11]. The policies of the company shape the culture, and the culture shapes the policies. Therefore the policies and culture of the company determine how alternatives are evaluated, and which alternatives are chosen.

The operational manager in a business that has a financial share in the business, will endeavour to increase the value of the share of the business. With an EVA bonus system, the operational manager should have the same aims, since it effectively converts the manager into a shareholder by tying his/her financial fortunes to the value drivers that will increase value for the owners. Therefore, the decisions that the manager must make on a day to day basis must be in some sense "good." In the case of management with EVA as a bonus system, a "good" decision should be one that increases the EVA of the business.

Consider now the person that is responsible for the production facility. It is important to increase return on investment, since this is a part of the EVA equation (see equation 2). Now, since every product in the production facility has a cost associated with the production of it, one way to increase return on investment would be to produce at the lowest possible cost. The production facility can gain the maximum returns on the equipment if it produces without internuption. To use large batch sizes reduce the number of times that setups need to be done on the equipment, therefore the facility can produce with less interruptions and therefore maximise return on investment. Consider in the same business, the person that is responsible for procurement. In this case, the person realises that working capital is mostly tied up in 
inventories, and to increase return on investment, the same output should be obtained with minimal investment. The procurement manager has several choices under his/her control to increase return on investment: one is to follow the approach in Figure 3, another is to minimise the cycle time that inventory passes through the system. A way to minimise the cycle time is to batch the items in production according to the end-item demand quantity [10]. If the procurement manager follows the first strategy, the danger is that too low inventories will result in lost sales due to stock-outs. If the procurement manager follows the second strategy, the production manager cannot increase return on investment by running the production facility as long as possible without changing the setups.

The local decisions of the production manager and the procurement manager are therefore in conflict, and most likely will lead to suboptimal outcomes in the system. This problem of system optimisation by optimising the parts, is one of the central characteristics of systems: "if each part of a system, considered separately, is made to operate as efficiently as possible, the system as whole will not operate as effectively as possible" [6]. This notion is also expressed in the following form: "the system optimum is not the sum of the local optima" [12].

\section{The conflict between local and global decisions}

From the previous paragraph, it is clear that decisions made within a business, can be in conflict with each other. These conflicts in the system are acknowledged by managers. The compromises that managers make to balance the trade-offs in the conflicts are part of the daily decision making process of managers. If it is assumed that rational decisions are made within the company, then there must exist some (unwritten) rules of decision making which creates the model for making business decisions. This model is influenced by the culture of the company, and the culture of the individual. This accepted model or pattern which is used for decision making is called a paradigm [13]. The nature of a paradigm forces a certain view of the world: ideas that do not fit in with that view tend to be ignored, misunderstood or explained away. A paradigm is both an assumption about reality, but also a commitment to how things are in this view of reality [14]. The question now arises: are the conflicts in a business an inevitable result of the structure of our businesses, or is the paradigm with which the business is managed leading to the above conflicts? To answer this question, the conflicts that managers face must be examined.

The conflicts in a system are also known as dilemmas. Ackoff [6] defines a dilemma in a system as "a problem or question that cannot be solved or answered within the prevailing world view and therefore calls it into question." By solving these dilemmas, it is possible to create a new world view. In extreme cases, this new world view is called a paradigm shift. (It is important to note that "paradigm shift" has entered into everyday use. Thomas S. Kuhn who has coined the phrase, refers to paradigm shifts as changes in world view such as the Copernican view of the solar system, Newton's laws of motion and Einstein's theory of relativity [13]. A paradigm shift is therefore a rare event in that it challenges all previously held beliefs, but also explains the dilemmas so well that it is recognised as the new world view. The current use of the term paradigm shift is therefore in most cases an inappropriate use of the term.) If the dilemma cannot be solved, then there are two other options open in the system: reduce choice to reduce conflict [6], or compromise between the conflicting needs [15]. 
The evaporating cloud. The conflicts in business as a system therefore seem to be a result of the view of the problem, and the assumptions behind these views. A method to surface the assumptions behind the conflicts, is the evaporating cloud [15]. The structure of the evaporating cloud is explained in Figure 5.

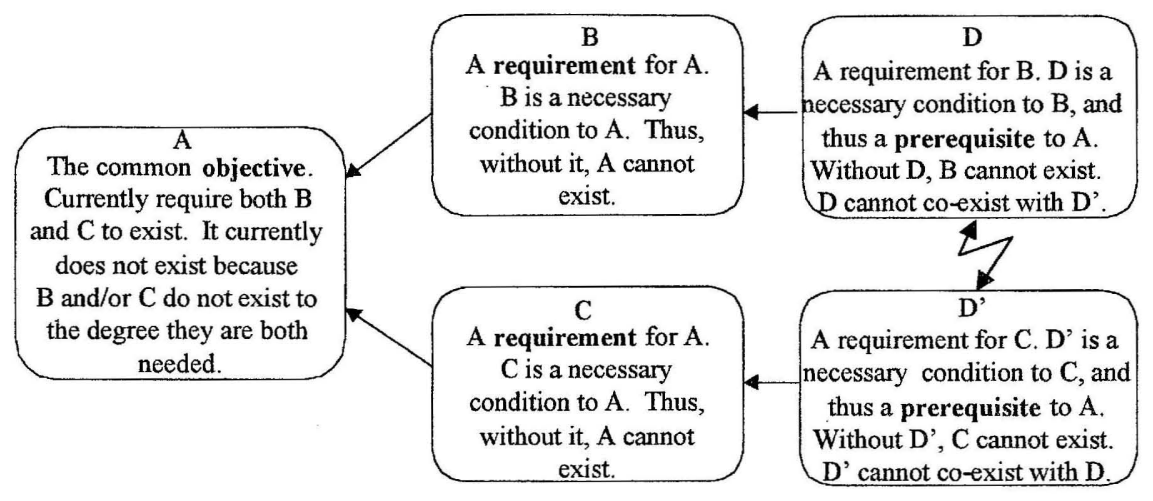

Figure 5. Structure of the evaporating cloud [16]

The inventor of the evaporating cloud, Eli Goldratt, explains it as follows: "The Evaporating Clouds method does not strive to reach a compromise solution, rather it concentrates on invalidating the problem itself. The first attack is made on the objective itself asking, 'Do we really want it?' . . . let's assume for now that the objective has been checked and verified. Yes, we do want to achieve this specific objective. Is the only way open to turn to the avenue of compromise? The answer is definitely not. What we have to remind ourselves of, is that the arrows in the Evaporating Clouds diagram, the arrows connecting the requirements to the objective, the prerequisite to the requirements and the arrow of conflict, all these arrows are just logical connections. One of the most basic fundamentals of logic is that behind any logical connection there is an assumption. In our case, most probably it is a hidden assumption. . . The Evaporating Clouds technique is based on verbalizing the assumptions hidden behind the arrows, forcing them out and challenging them. It's enough to invalidate even one of these assumptions, no matter which one, and the problem collapses, disappears." [17]

An example of a conflict found in most companies is illustrated in Figure 6. The evaporating cloud in Figure 6 is read as follows: in order for our compensation scheme to motivate salespeople to increase the company's profit (A), the salespeople must feel that their performance measure fairly reflects their own efforts (B). And, in order for salespeople to feel their performance measure fairly reflects their own efforts (B), compensation must be tied only to elements that the salespeople can control (D). Also, in order for our compensation scheme to motivate salespeople to increase the company's profit (A), compensation must be tied to the company profits (C). And, in order for the compensation scheme to be tied to the company profits (C), compensation must be tied to elements salespeople cannot control (e.g. production costs) $\left(\mathrm{D}^{\prime}\right)$. 


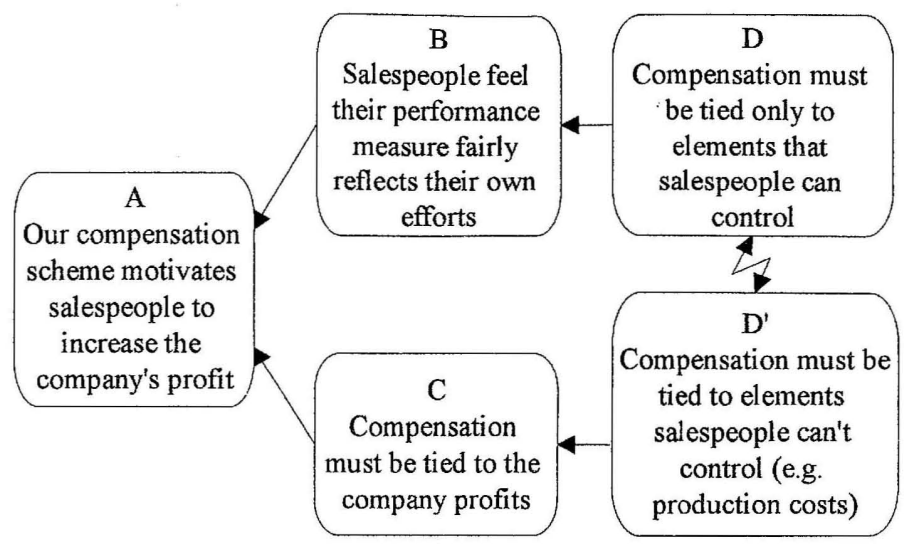

Figure 6. Performance bonus conflict (Based on [17])

The three-cloud technique. It is possible to resolve the performance bonus conflict in Figure 6 as a stand-alone problem. However, to gain a deeper understanding of reality, it is possible to find what the core, underlying struggle in the conflict is. This is done via a method of correlation between daily problems and their symptoms, and to clearly verbalise these symptoms so that some generalities can be observed. Usually, it is sufficient to use three symptoms, and express these three symptoms as clouds. Therefore the method is called the three-cloud technique. The three clouds generated from the three symptoms are then examined to look for a pattern between them. Almost always, there will be a discernible general pattern in the clouds from which a broader, generic cloud can be constructed. This generic cloud contains the core conflict in the subject matter [10].

There is already one organisational conflict available in Figure 6. It is therefore only necessary to construct clouds for two more conflicts: in this example one conflict from the production manager and one conflict from the procurement manager should give a broad enough view of symptoms across organisational boundaries. One would not expect to find the same underlying problem in three different areas of the organisation.

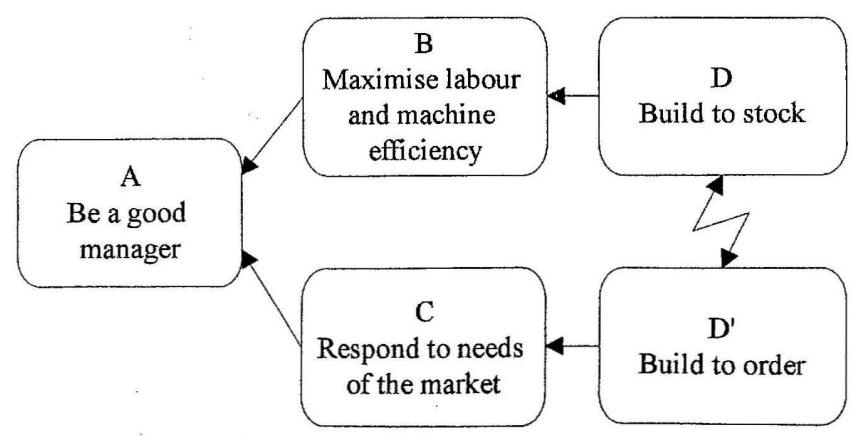

Figure 7. Production management conflict (Based on [10]) 
The production manager faces the conflict in Figure 7. The cloud of the production manager is read as follows: in order to be a good manager (A), the efficiency of labour and machinery must be maximised (B). And, in order to maximise the efficiency of labour and machinery (B), it is necessary to build to stock (D). Also, in order to be a good manager (A), production must respond to the needs of the market $(\mathrm{C})$. And, in order to respond to the needs of the market, it is necessary to build to order $\left(D^{\prime}\right)$.

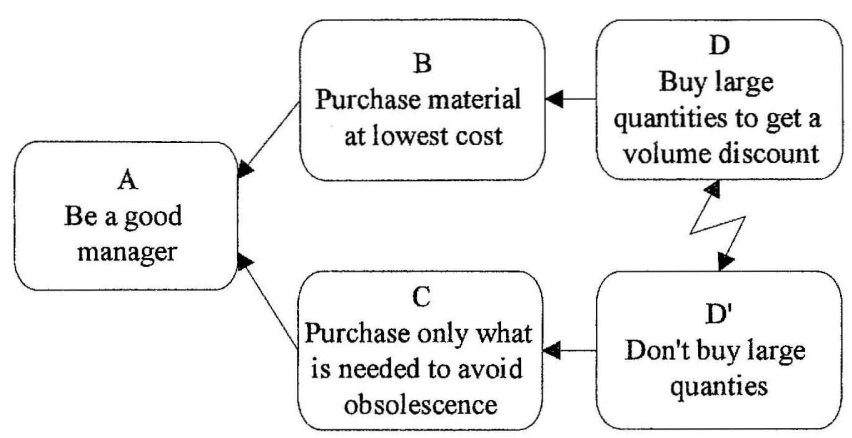

Figure 8. Procurement management conflict (Based on [10])

The procurement manager faces the conflict in Figure 8. The cloud of the procurement manager is read as follows: in order to be a good manager (A), material must be purchased at the lowest cost (B). And, in order to purchase material at the lowest cost (B), it is necessary to buy in large quantities to get a volume discount (D). Also, in order to be a good manager (A), only what is needed must be purchased to avoid obsolescence (C). And, in order to purchase only what is needed to avoid obsolescence (C), large quantities must not be bought (D').

The next step is to examine the conflicts in Figures 6,7 and 8 in order to try and find commonality between the elements of the conflicts:

Element A: Two of the clouds have the same objective: to be a good manager. However, to design a compensation scheme that motivates salespeople to increase the company's profits, is also part of being a good manager. The generic element is therefore to be a good manager.

Element B: In this case there are seemingly different requirements: salespeople must feel that their performance measure is fairly reflecting their contribution, for the production manager it is to maximise the efficiency of labour and machinery, for the procurement manager it is to buy at the lowest cost. The common element is to manage what is within the span of control of each of the different managers. The cost of operation of the department is under the control of each manager. Therefore, a possible generic element is to control cost.

Element D: Again there are quite different prerequisites to the objective: salespeople's compensation must be tied to elements under their control, production must build to stock when the machines and labour are available, and the procurement manager must buy large quantities in order to secure low prices. The common element is the local decision that is open to the manager: to control the cost to the company, it is necessary to judge according to the local impact on cost. The common element is therefore to judge according to the local impact. 
Element C: The requirements to the objective are as follows: the compensation scheme of sales-people must be tied to the profit of the company, the production manager must be tied to the needs of the market, and the procurement manager must prevent losses to the company due to obsolescence of material. The common element here is to protect the profitability of the company.

Element D': The prerequisites to the objective are as follows: the compensation scheme of the salespeople must be tied to factors outside the salespeople's control, the production manager must sacrifice efficiency of labour and machinery to build to order, and the procurement manager must buy in small quantities at a higher cost. These are all factors which have a global impact (on profit), rather than being the best local decision. The common element is therefore to not judge according to the local impact.

The generic management conflict. The three-cloud analysis of the conflicts facing managers can be used to create the generic management conflict illustrated in Figure 9.

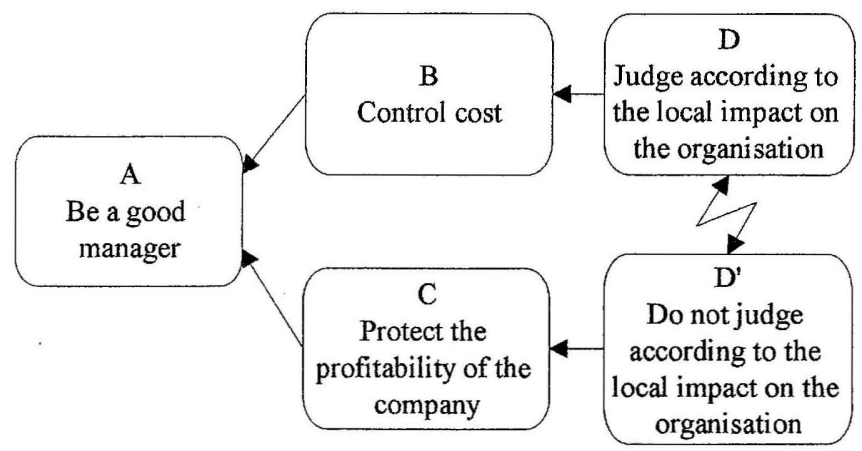

Figure 9. Generic management conflict (Based on [18])

The cloud is read as follows: in order to be a good manager (A), it is necessary to control costs (B). And, to control costs (B), judgements must be made on the local (cost) impact on the organisation (D). Also, in order to be a good manager (A), the profitability of the organisation must be protected (C). And, in order to protect the profitability of the organisation, it is necessary to not judge according to the local impact on the organisation (D').

The next step is to identify the assumptions that are underlying the logic of the generic management conflict. A method to identify the assumptions is to read a logical part of the cloud, and then add the word "because" [16]. The part of the sentence that follows the word "because" is one of the assumptions urderlying the logical sequence. The B-D part of the generic management cloud can be read as follows: In order to control cost, judgements must be made according to the local impact on the organisation because . . "local impact is equal to impact on the organisation" [18]. In the same way, the $\mathrm{B}-\mathrm{D}^{\prime}$ part of the generic management cloud can be read as follows: In order to protect the profitability of the company, judgements must not be made according to the local impact on the organisation because ... "local impact is NOT equal to impact on the organisation" [18].

However, a general principle in systems theory is that the local impact is not an indication of the global impact. Therefore, the B-D part of the generic management conflict is not valid 
since it is based on a wrong assumption about systems (and business is a system). It is true that in order to be a good manager, it is necessary to control costs. However, it is not true that local cost optimising decisions are (always) good for the business. In fact, cost as a decision making paradigm can only be valid if the local cost impact of a decision is proportional to the global profit impact on the company, which it certainly is not [19]. The generic management conflict is therefore resolved, if a method can be found to make local decisions that will have the correct global impact on the organisation. This method must be a systems approach, since by applying the method the manager must be able to judge the impact of seemingly insignificant local decisions on the organisation as a whole. Goldratt's Theory of Constraints [20] is a systems approach that enables the manager to make local decisions within a coherent global framework.

\section{Conclusions}

In order to understand how decisions are made in a business, a basic understanding of systems and business as a system is needed. The most important aspects of systems and systems thinking that is needed to gain insight into a business is a realisation that a system has emergent properties, that cause and effect can be non-linear and far removed in time and space, and that unwanted side-effects can be caused by well-intentioned actions. The EVA of the business is an emergent property of the organisation as a system. Methods that manage EVA by splitting it into constituent parts will be most likely unsuccessful due to the counterintuitive outcomes of the cause and effect relationships. These cause and effect relationships can be mapped with causal loop diagrams. By examining the systems archetypes in causal loop diagrams, it is possible to diagnose recurrent problems in systems.

The conflict between opposing actions in a system, creates an opportunity to examine the paradigm that is used for decision making within the system. By examining the correlation between seemingly different conflicts that managers in a company face daily, it is possible to deduce the core problem that underpins management decision making within the current paradigm: that the positive local impact of a decision leads to a positive global impact.

This method of management (of extrapolating local impact to the global impact), is based on a faulty assumption about systems. It is a principle of systems that local optimisations leads to a global suboptimum. Therefore it is necessary to manage a company according to a systems approach: the Theory of Constraints is such a systems approach.

\section{References}

[1] Allan A. Kennedy. The end of shareholder value: the real effects of the shareholder value phenomenon and the crisis it is bringing to business. Orion Business, London, 2000.

[2] Alfred Rappaport. Creating shareholder value: a guide for managers and investors. The Free Press, New York, 2nd edition, 1998.

[3] G. Bennett Stewart. The quest for value: the EVA(TM) management guide. HarperCollins, 1990.

[4] Gary C. Biddle, Robert M. Bowen, and James S. Wallace. Economic value added: some empirical EVAdence. Managerial Finance, 24 no 11:60-71, 1998.

[5] Joseph O'Connor and Ian McDermott. The art of systems thinking: essential skills for creativity and problem solving. Thorsons, London, 1997. 
[6] Russell L. Ackoff. Ackoff 's best: his classic writings on management. John Wiley \& Sons, New York, 1999.

[7] Jamshid Gharajedaghi. Systems thinking: managing chaos and complexity: a platform for de-signing business architecture. Butterworth-Heinemann, Boston, 1999.

[8] H. William Dettmer. Breaking the constraints to world-class performance. American Society for Quality, Milwaukee, 1998.

[9] Daniel H. Kim and Virginia Anderson. Systems archetype basics: from story to structure. Pegasus Communications, Waltham, 1998.

[10] Debra Smith. The measurement nightmare: how the theory of constraints can resolve conflicting strategies, policies and measures. St. Lucie Press/APICS series on constraints management. St. Lucie Press, Boca Raton, 2000.

[11] Tim Hindle. Guide to management ideas. The Economist books. Profile Books, London, 2000.

[12] H. William Dettmer. Goldratt's theory of constraints: a systems approach to continuous improvement. American Society for Quality, Milwaukee, 1997.

[13] Thomas S. Kuhn. The structure of scientific revolutions. University of Chicago, 2nd enlarged edition, 1970.

[14] Donella H. Meadows. System dynamics meets the press. The Global Citizen, pages 1$12,1991$.

[15] Eliyahu M. Goldratt. It's not luck. Avraham Y. Goldratt Institute, Pretoria, 1994.

[16] Lisa J. Scheinkopf. Thinking for a change: putting the TOC thinking processes to use. St. Lucie Press/APICS series on constraints management. St. Lucie Press, Boca Raton, 1999.

[17] Eric Noreen, Debra Smith, and James T. Mackey. The theory of constraints and its implications for management accounting. North River Press, Great Barrington, 1995.

[18] Eliyahu M. Goldratt. Goldratt satellite programme viewer notebook. 1999.

[19] Eliyahu M. Goldratt. Essays on the theory of constraints. North River Press, Great Barrington, 1987-1990.

[20] Eliyahu M. Goldratt and Jeff Cox. The goal: a process of ongoing improvement. Avraham Y. Goldratt Institute, Pretoria, 2nd revised edition, 1992. 